\title{
Monoclonal Antibody Therapy and Long-term Outcomes in Multiple Sclerosis - The Challenge of Treatment Optimisation
}

\author{
Antonio Scalfari and Paolo A Muraro \\ Department of Medicine, Division of Brain Sciences, Imperial College London, Hammersmith Hospital Campus, London, UK
}

DOI: https://doi.org/10.17925/ENR.2018.13.2.78

\begin{abstract}
$\mathrm{T}$ he therapeutic landscape of multiple sclerosis (MS) has been transformed by the advent of several new monoclonal antibody (MAb) therapies that can potentially lead to full stabilisation of detectable disease activity. Natalizumab, alemtuzumab and ocrelizumab are currently licensed MAbs for the treatment of MS. Daclizumab was licensed for the treatment of MS, although it has been recently withdrawn from the market by the manufacturer. Most patients are initially managed with first-line treatments, and, if disease breakthrough occurs, are escalated to a stronger compound, yet the available evidence indicates an early window of therapeutic opportunity for MAbs to exert most of their efficacy. It is important to balance the superior efficacy of MAbs compared with injectable treatments against more serious side effects, although these are well recognised and can be monitored where indicated and treated. In particular, the risk of progressive multifocal leucoencephalopathy with natalizumab can be managed by screening potential patients for the John Cunningham virus. The MAbs also have the benefit of convenience to patients compared with daily or weekly treatments since they are given via less frequent administration. The cost of these treatments, compared with other therapies, may be an important issue in many countries where healthcare budgets are under pressure. The complex decision of choosing the best treatment for an individual should be made jointly between the doctor and the patient after careful consideration of the many factors to be weighed.
\end{abstract}

\section{Keywords}

Multiple sclerosis, monoclonal antibody, treatment switching, natalizumab, alemtuzumab, daclizumab, ocrelizumab

Disclosures: Antonio Scalfari has nothing to disclose in relation to this article. Paolo A Muraro has nothing to disclose in relation to this article, but has received non-financial support from the National Institute for Health Research (NIHR) Biomedical Research Centre funding scheme to Imperial College London and during the conduct of the study received travel, personal fees and non-financial support from Merck Serono and Bayer. He has also received personal fees from Biogen and from Novartis, outside the submitted work.

Review Process: Double-blind peer review.

Acknowledgements: Medical writing support, including preparation of the drafts under the guidance of the authors, was provided by Ray Ashton at Touch Medical Media and funded by Roche.

Authorship: All named authors meet the criteria of the International Committee of Medical Journal Editors for the authorship for this manuscript, take responsibility for the integrity of the work as a whole and have given final approval for the version to be published open Access: This article is published under the Creative Commons Attribution Noncommercial License, which permits any non-commercial use, distribution, adaptation and reproduction provided the original author(s) and source are given appropriate credit. (c) The Authors 2018.

Received: 31 August 2018

Accepted: 18 September 2018

Citation: European Neurological Review. 2018;13(2):78-85

Corresponding author: Dr Antonio Scalfari. Department of Medicine, Division of Brain Sciences, Imperial College London, Hammersmith Hospital Campus, Burlington Danes Building, Du Cane Road, LondonW12 ONN UK. F· a scalfari@imperial ac.uk

Support: The publication of this article was supported by Roche, who were given the opportunity to review the article for scientific accuracy before submission. Any resulting changes were made at the authors' discretion.
Multiple sclerosis (MS) is a chronic, autoimmune disease of the central nervous system (CNS), which has an enormous social and economic cost.' In most cases ( 85\%), the disease course is initially characterised by clinical exacerbations (relapses), which occur with a relatively random pattern and can be followed by partial or complete recovery. After a variable length of time from the disease onset, the majority of patients with a relapsing-remitting (RR) course enter the secondary progressive (SP) phase, ${ }^{2}$ which leads to the gradual accumulation of severe disability, exerting the most significant disease burden. Relapses are underlined by focal inflammation and demyelination of the CNS white matter. However, the axonal damage and neurodegeneration are the pathological substrate of permanent disability and are known to occur early in the disease course ${ }^{3}$ much before the clinical onset of the progressive phase. The relationship between focal inflammation and degenerative mechanisms remains uncertain and has important implications for therapeutic strategies. ${ }^{4}$

Over the last two decades, the therapeutic landscape has dramatically evolved with the development of several new treatments for relapse-remitting multiple sclerosis (RRMS), which can potentially lead to full stabilisation of the disease activity parameters and even improve function in a subset of patients. ${ }^{5}$ However, preventing or delaying the onset of the progressive phase remains a major unmet therapeutic need. ${ }^{6}$ Monoclonal antibodies (MAbs) can achieve the highest suppression of the focal inflammatory activity, albeit at the cost of exposing patients to higher risk of severe adverse events (AES). In this review, we focus on MAbs that are currently used for treating MS or that will be approved by regulatory agencies soon, and we discuss their role in therapeutic strategies.

\section{The potential impact of monoclonal antibodies on long-term outcomes in multiple sclerosis Natalizumab}

Natalizumab is currently approved for the treatment of patients with MS with clinically and radiologically active disease. It is a selective adhesion-molecule inhibitor that binds to the leukocyte $\alpha_{4}$ subunit of $\alpha_{4} \beta_{1}$ and $\alpha_{4} \beta_{7}$ integrins, preventing their adhesion to endothelial receptors. Its efficacy was evaluated in a multicentre, randomised, placebo-controlled, 120-week trial, which enrolled 942 patients with RRMS (Natalizumab Safety and Efficacy in Relapsing Remitting Multiple Sclerosis [AFFIRM] study). ${ }^{7,8}$ Most measures of clinical and radiological disease activity were significantly reduced by natalizumab administered over 2 years, compared with placebo (Table 1). ${ }^{7.8}$ 
Table 1: Summary of phase III study results with disease-modifying therapies

\begin{tabular}{|c|c|c|c|c|}
\hline DMT & MRI & ARR & EDSS/disability progression & AEs (\%) \\
\hline \multicolumn{5}{|l|}{ Natalizumab } \\
\hline $\mathrm{AFFIRM}^{7,8}$ & $\begin{array}{l}\text { 83\% reduction T2 ( } p<0.001), 76 \% \text { T1 new or } \\
\text { enlarging hypointense lesions ( } p<0.001) \text {, } \\
\text { 92\% fewer Gd-enhancing lesions ( } p<0.001 \text { ) } \\
\text { versus placebo }\end{array}$ & $68 \%$ reduction $(p<0.001)$ & $\begin{array}{l}\text { Cumulative probability of } \\
\text { progression } 17 \% \text { versus } 29 \%, \\
p<0.001 \text { versus placebo }\end{array}$ & $\begin{array}{l}\text { Significantly more frequent } \\
\text { versus placebo: fatigue ( } 27 \\
\text { versus } 21 ; p=0.048) \text {, allergic } \\
\text { reaction ( } 9 \text { versus } 4, p=0.012 \text { ) }\end{array}$ \\
\hline STRATA $^{10,11}$ & Not reported & 0.15/patient/year & $\begin{array}{l}2.9 \text { and } 3.2 \text { at week } 288 \\
\text { versus placebo }\end{array}$ & $\begin{array}{l}\text { SAES (16); PML (14 cases), } \\
\text { infusion reaction ( } 5 \text { at } \\
48 \text { weeks), infections (4), } \\
\text { GI disorders (2), neoplasms (2) }\end{array}$ \\
\hline TOP $^{12}$ & Not reported & $\begin{array}{l}0.31 \text { versus } 1.99 \text { at baseline } \\
(p<0.0001)\end{array}$ & $\begin{array}{l}3.3 \text { after } 4 \text { years versus } 3.5 \\
\text { at baseline }\end{array}$ & $\begin{array}{l}\text { SAES (8); PML (0.4), infection } \\
(1.9), \text { hypersensitivity reaction } \\
(0.5), \text { malignancy }(0.5)\end{array}$ \\
\hline \multicolumn{5}{|l|}{ Alemtuzumab } \\
\hline CARE-MS I ${ }^{18}$ & $\begin{array}{l}\text { IFN } \beta-1 \text { a versus alemtuzumab: median change } \\
\text { in T2 lesion volume; }-6.5 \% \text { (-20.7-2.5), }-9.3 \% \\
(-19.6-0.2) p=0.31 \text {. New/enlarging T2 lesions; } \\
58 \% \text { versus } 48 \% p=0.04 \text {. Gd-enhancing lesions } \\
19 \% \text { versus } 7 \%, p<0.0001 . \text { Median change in } \\
\text { brain parenchymal fraction; }-1.488 \% \\
(-2.355--0.567) \text { versus }-0.867(-1.470--0.254) \\
p<0.0001\end{array}$ & $\begin{array}{l}\text { 22\% versus } 40 \% \text { relapsed } \\
\text { (alemtuzumab versus IFN } \beta-1 a \text { ) }\end{array}$ & $\begin{array}{l}0.14 \text { point improvement with } \\
\text { alemtuzumab or IFN } \beta-1 a \text {. } \\
\text { Sustained accumulation } \\
\text { disability } 8 \% \text { versus } 11 \% \text {, } \\
\text { p=0.02 (IFN } \beta \text {-1a versus } \\
\text { alemtuzumab) }\end{array}$ & $\begin{array}{l}\text { Infusion-associated reactions } \\
\text { (90), infections (67 versus } 45 \\
\text { IFN } \beta-1 a) \text {, thyroid-associated } \\
(18 \text { versus } 6 \text { IFN } \beta-1 a)\end{array}$ \\
\hline CARE-MS $\|^{19}$ & $\begin{array}{l}\text { IFN } \beta-1 \text { a versus alemtuzumab: median change } \\
\text { in T2 lesion volume; }-1.23(-11.13-11.39),-1.27 \\
(-12.7-7.78) p=0.14 \text {. New/enlarging T2 lesions; } \\
68 \% \text { versus } 46 \% p<0.0001 \text {. Gd-enhancing } \\
\text { lesions } 23 \% \text { versus } 9 \%, p<0.0001 \text {. Median } \\
\text { change in brain parenchymal fraction; }-1.810 \% \\
(-1.539-0.203) \text { versus }-0.615(-1.299-0.006) \\
p=0.01\end{array}$ & $\begin{array}{l}\text { 51\% versus } 35 \% \text { relapsed } \\
\text { (IFN } \beta \text {-1a versus alemtuzumab) }\end{array}$ & $\begin{array}{l}0.24 \text { versus }-0.17, p<0.0001 \\
\text { Sustained accumulation } \\
\text { disability } 20 \% \text { versus } 13 \% \\
p=0.0084 \text { (IFN } \beta-1 \text { a versus } \\
\text { alemtuzumab) }\end{array}$ & $\begin{array}{l}\text { Infusion-associated reactions } \\
(90) \text {, infections (77 versus } 66 \\
\text { IFN } \beta-1 a) \text {, thyroid-associated } \\
\text { (16 versus } 6 \text { IFN } \beta-1 a)\end{array}$ \\
\hline $\begin{array}{l}\text { CARE-MS I extension } \\
(5 \text { years })^{21}\end{array}$ & Not reported & $0.19(Y 3), 0.15(Y 5)$ & 69\% stable/improved & $\begin{array}{l}\text { Incidence of SAEs low, } \\
\text { infusion-associated reactions, } \\
\text { infections reduced }\end{array}$ \\
\hline $\begin{array}{l}\text { CARE-MS II extension } \\
(5 \text { years })^{22}\end{array}$ & Not reported & $0.22(Y 3), 0.18(Y 5)$ & 65\% stable/improved & $\begin{array}{l}\text { Incidence of SAEs low, } \\
\text { infusion-associated reactions, } \\
\text { infections reduced }\end{array}$ \\
\hline \multicolumn{5}{|l|}{ Ocrelizumab } \\
\hline OPERA $\left.\right|^{34}$ & $\begin{array}{l}\text { IFN } \beta \text {-1a versus ocrelizumab: } \% \text { with T2 lesions; } \\
61.3 \text { versus } 38.3 \text {. Hyperintense T1 lesions (rate } \\
\text { ratio); } 0.43(0.33-0.56, p<0.001) \text {. Gd-enhancing } \\
\text { T1 lesions } 30.2 \% \text { versus } 8.3 \% \text {. Difference }(\%) \text { in } \\
\text { rate of brain volume loss; }-22.8, p=0.004\end{array}$ & $\begin{array}{l}0.29 \text { versus } 0.16 \text { (IFN } \beta-1 a \\
\text { versus ocrelizumab). } 46 \% \\
\text { lower ARR (ocrelizumab versus } \\
\text { IFN } \beta-1 a, p<0.001 \text { ) }\end{array}$ & $\begin{array}{l}\text { Pooled analysis: } 13.6 \% \\
\text { with disability progression } \\
\text { versus } 9.1 \% \text { (IFN } \beta-1 \text { a versus } \\
\text { ocrelizumab). } 40 \% \text { lower risk } \\
\text { (ocrelizumab versus IFN } \beta-1 a, \\
p<0.001 \text { ) }\end{array}$ & $\begin{array}{l}\text { SAEs } 7.8 \text { versus } 6.9 \text {, infections } \\
54.3 \% \text { versus } 56.9 \% \text {, } \\
\text { infusion-related reactions } 7.3 \% \\
\text { versus } 30.9 \% \text {, neoplasms } 0.5 \% \\
\text { versus } 0.2 \% \text { in pooled analysis } \\
\text { (IFN } \beta-1 \text { a versus ocrelizumab) }\end{array}$ \\
\hline OPERA $\|^{34}$ & $\begin{array}{l}\text { IFN } \beta \text {-1a versus ocrelizumab: } \% \text { with T2 lesions; } \\
62.0 \text { versus 39.1. Hyperintense T1 lesions (rate } \\
\text { ratio); } 0.36(0.27-0.47, p<0.001) \text {. Gd-enhancing } \\
\text { T1 lesions } 36.1 \% \text { versus } 9.8 \% \text {. Difference (\%) in } \\
\text { rate of brain volume loss; } 14.9, p=0.09\end{array}$ & $\begin{array}{l}0.29 \text { versus } 0.16 \text { (IFN } \beta-1 a \\
\text { versus ocrelizumab). } 47 \% \\
\text { lower ARR (ocrelizumab versus } \\
\text { IFN } \beta-1 a, p<0.001 \text { ) }\end{array}$ & $\begin{array}{l}\text { Pooled analysis: } 13.6 \% \\
\text { with disability progression } \\
\text { versus } 9.1 \% \text { (IFN } \beta \text {-1a versus } \\
\text { ocrelizumab). } 40 \% \text { lower risk } \\
\text { (ocrelizumab versus IFN } \beta-1 a, \\
p<0.001 \text { ) }\end{array}$ & $\begin{array}{l}\text { SAEs } 9.6 \text { versus } 7.0 \text {, infections } \\
52.5 \% \text { versus } 60.2 \% \text {, } \\
\text { infusion-related reactions } 12.0 \% \\
\text { versus } 37.6 \% \text {, neoplasms } 0.5 \% \\
\text { versus } 0.2 \% \text { in pooled analysis } \\
\text { (IFN } \beta-1 \text { a versus ocrelizumab) }\end{array}$ \\
\hline ORATORIO ${ }^{33}$ & $\begin{array}{l}\text { Total brain lesion volume (\%) }-3.4 \% \text { versus } \\
7.4 \%, p<0.001 \text {. Brain-volume loss } 0.9 \% \text { versus } \\
1.09 \%, p=0.02 \text { (ocrelizumab versus placebo) }\end{array}$ & Not reported & $\begin{array}{l}\text { Patients with disability } \\
\text { progression (\%) } 32.9 \% \text { versus } \\
39.3 \%, p=0.03 \text { (ocrelizumab } \\
\text { versus placebo) }\end{array}$ & $\begin{array}{l}\text { SAEs } 20.4 \% \text { versus } 22.2 \% \text {, } \\
\text { serious infections } 6.2 \% \text { versus } \\
5.9 \% \text {, infusion-related reactions } \\
39.9 \% \text { versus } 25.5 \% \text {, neoplasms } \\
2.3 \% \text { versus } 0.8 \% \text { (ocrelizumab } \\
\text { versus placebo) }\end{array}$ \\
\hline
\end{tabular}

AES = adverse events; AFFIRM = Natalizumab Safety and Efficacy in Relapsing Remitting Multiple Sclerosis; $A R R=$ annualised relapse rate; $C A R E-M S=$ Comparison of Alemtuzumab and Rebif $\oplus^{-}$Efficacy in Multiple Sclerosis; DMT = disease-modifying therapy; EDSS = Expanded Disability Status Scale; $G d=$ gadolinium; $G I=$ gastrointestinal; IFN $\beta$-1a = interferon beta-1a; MRI = magnetic resonance imaging; PML = progressive multifocal leukoencephalopathy; SAES = serious adverse events; STRATA = Safety of Tysabri Re-dosing and Treatment; $T O P=$ Tysabri Observational Program; $Y=$ year . 
Figure 1: STRATA study with natalizumab - annualised relapse rate over time

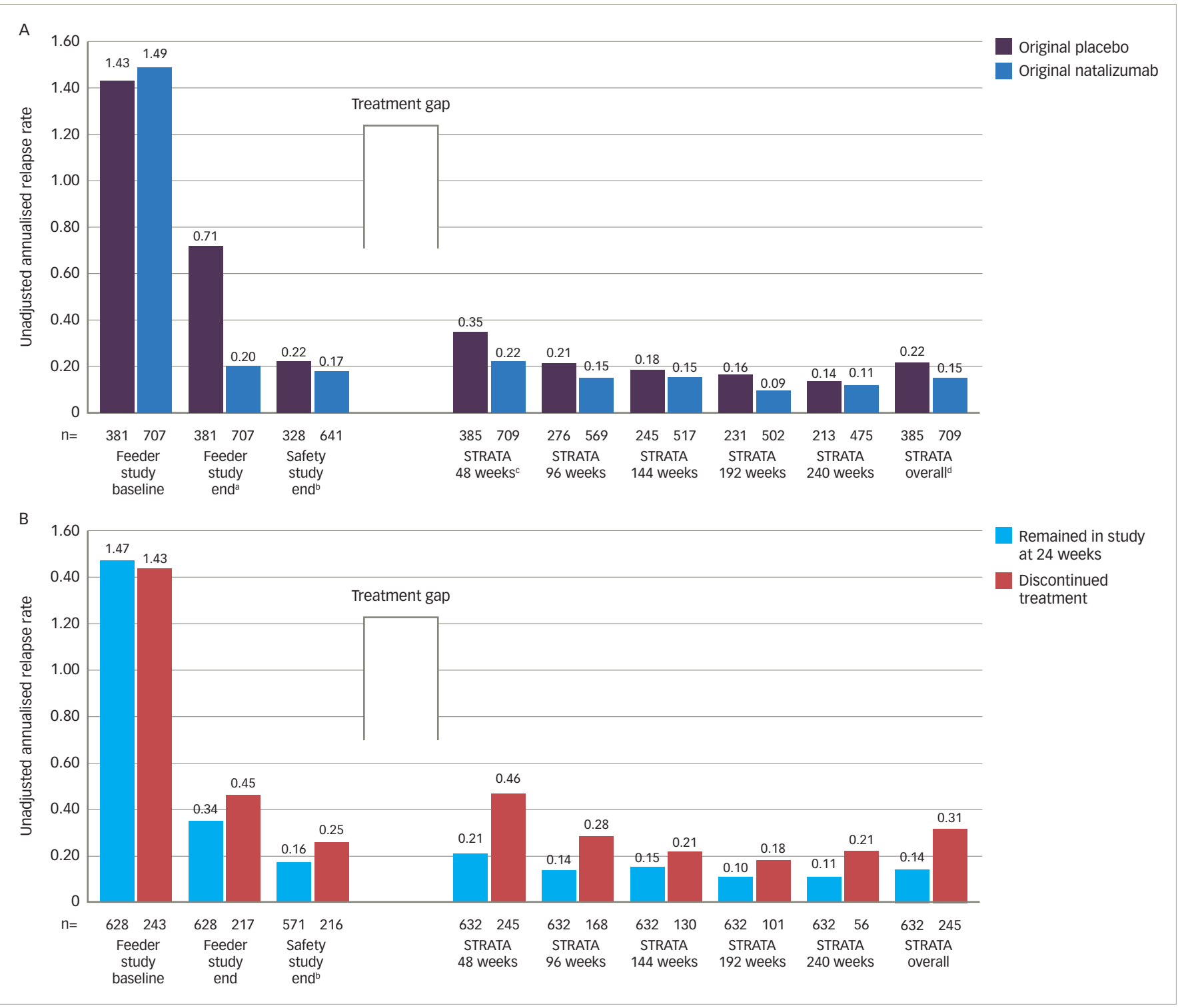

(A) By original treatment assignment in feeder studies. Reflects all available on-treatment relapse data during the STRATA Study. ${ }^{a} p<0.0001$ for comparison between original assignment to placebo versus original assignment to natalizumab. ${ }^{b}$ Includes data on patients dosed with natalizumab. ${ }^{c} p<0.01$ for comparison between original assignment to placebo versus original assignment to natalizumab. ${ }^{d} p<0.001$ for comparison between original assignment to placebo versus original assignment to natalizumab.

(B) By continuation of treatment status in STRATA (at or have not yet reached week 240 versus discontinued treatment before week 240 ). Includes all available on-treatment relapse data for natalizumab and placebo groups in STRATA combined. 'Dincludes data on patients dosed with natalizumab.

STRATA = Safety of TYSABRI Re-dosing and Treatment.

Reproduced with permission from O'Connor et al., 2014. ${ }^{10}$

Currently, there are two ongoing large, open label, long-term follow-up studies of patients treated with natalizumab: Safety of Tysabri Redosing and Treatment (STRATA) and Tysabri Observation Program (TOP). ${ }^{9}$ STRATA included patients with RRMS from the AFFIRM, Safety and Efficacy of Natalizumab in Combination with Interferon Beta-1a (IFNß-1a) in Patients with RRMS (SENTINEL) and Glatiramer Acetate and Natalizumab Combination Evaluation (GLANCE) trials and their open-label extensions. Over the 5-year observation period, patients initially randomised to natalizumab rather than placebo or another disease-modifying therapy (DMT) had a lower annualised relapse rate (ARR) (Figure 1) and stable Expanded Disability Status Scale (EDSS) scores (3,460 patient-years at the time of this analysis). ${ }^{10}$ The 6-year analysis (20 March 2013), which included 4,135 patient-years of natalizumab exposure, showed that the EDSS scores and ARR remained stable in natalizumab-treated patients, confirming the positive long-term effect of early treatment with natalizumab, compared with patients who initially received placebo.11
The TOP study is a multinational, prospective, open-label, postmarketing, observational study of patients with RRMS, who had previously been treatment-naïve or had failed to respond to other DMTs and were enrolled shortly after starting natalizumab $(\leq 3$ infusions). Among 4,821 patients (enrolled by 1 December 2012), the ARR decreased from $1.99(1.95-2.03)$ in the 12 months prior to baseline to $0.31(0.29-0.32)(p<0.0001) .{ }^{12}$ For each year of natalizumab exposure, ARR increased from 0.21 to 0.30 , and mean EDSS remained relatively unchanged (3.5 at baseline, 3.3 at year 4).

In addition, data indicate that a substantial proportion of patients treated with natalizumab can achieve a no evidence of disease activity (NEDA) status (i.e. no relapses or disability progression on clinical measures and no activity on radiological measures). ${ }^{13}$ For example, this was reported in $37 \%$ of the natalizumab-treated group (compared with $7 \%$ of placebo group) from the AFFIRM trial and in 34\% of 152 
Figure 2: Observational cohort study with alemtuzumab - disability assessment ${ }^{24}$

A. Six-month sustained accumulation disability

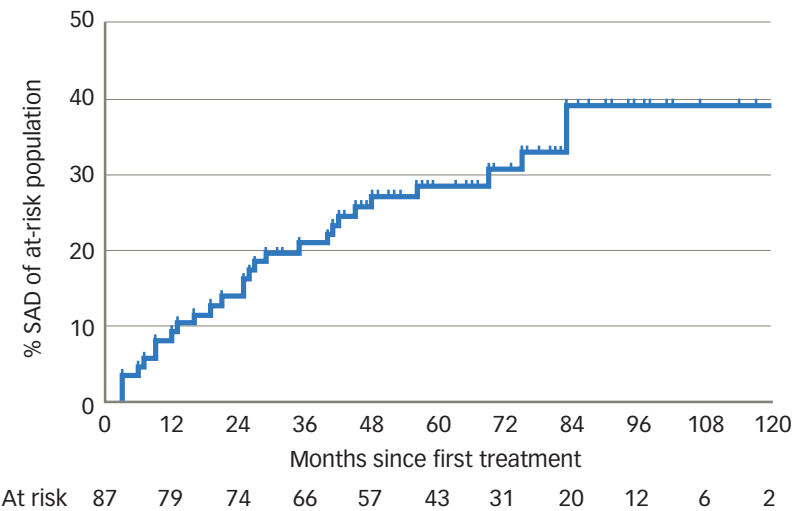

C. Twelve-month sustained accumulation disability

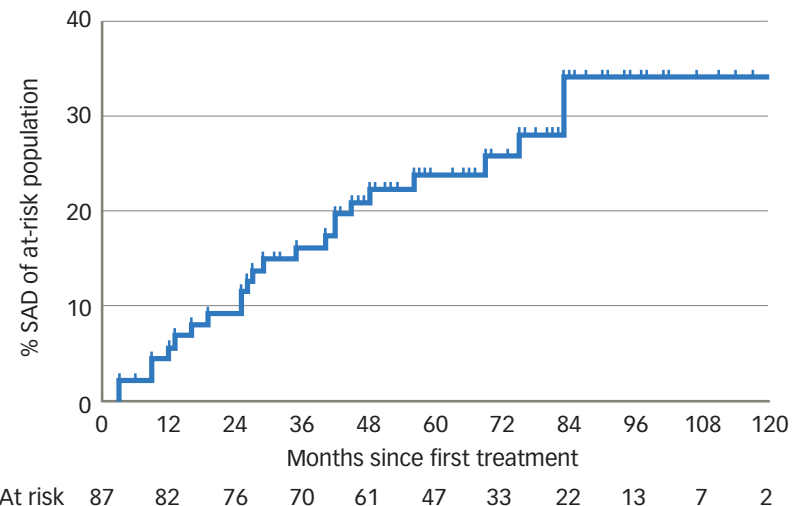

B. Six-month sustained reduction in disability

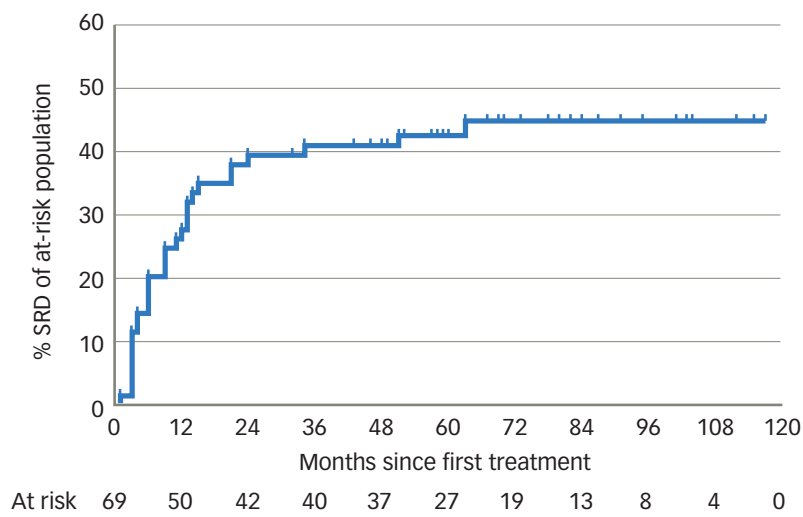

D. Twelve-month sustained reduction in disability

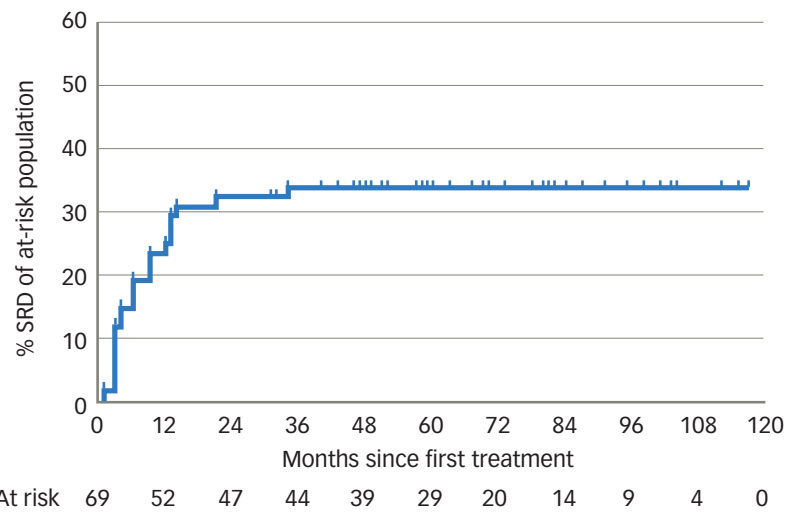

SAD = sustained accumulation of disability; $S R D=$ sustained reduction in disability. Reproduced with permission from Tuohy et al., $2015 .{ }^{24}$

natalizumab-treated patients observed for 7 years in a longitudinal study. ${ }^{14,15}$ Similarly, a retrospective, observational 44 -week study showed that $62 \%$ of 45 patients who initiated natalizumab after experiencing relapses on treatment showed no clinical or radiological signs of disease activity. ${ }^{16}$

Natalizumab-treated patients are at risk of developing progressive multifocal leukoencephalopathy (PML), which is a potentially fatal infection of the CNS caused by the John Cunningham virus (JCV). As of 7 December 2017, there have been 756 confirmed cases (753 with MS, 3 with Crohn's Disease) and $76.5 \%$ of patients were alive with varying degrees of disability. The overall incidence of PML was 4.19 per 1000 patients (as of 30 November 2017). ${ }^{17}$ Data showed that PML is more likely to occur, among patients with a high $(>1.50)$ titre of anti-JCV antibodies, long treatment duration (especially beyond 2 years) and previous immunosuppressant use. Other potential AES include fatigue, pharyngitis, allergic reactions, liver injury and other opportunistic infections, such as human herpesvirus-6 (HHV-6). ${ }^{9}$

\section{Alemtuzumab}

Alemtuzumab is approved for treating patients with active RRMS. It is a humanised MAb and although its mode of action has not been completely elucidated, it is known to selectively target CD52 antigens on both B- and T-lymphocytes, causing their depletion. Its efficacy was tested, compared to high-dose subcutaneous IFN $\beta$-1a in two randomised, controlled trials (CARE-MS I and II), 18,19 among patients who were treatment-naïve or previously received DMTs, respectively. In both studies, alemtuzumab was shown to exert higher clinical and MRI efficacy (Table 1). Over the 2-year observation period, patients treated with alemtuzumab had lower annualised relapse rates and reduced risk of sustained accumulation of disability, compared with the IFN $\beta$ 1a group. However, there was no difference in the accumulation of T2-hyperintense lesions volume between the two treatment groups, in both CARE-MS I or CARE-MS II. Importantly, alemtuzumab has also been shown to slow the rate of brain atrophy by $42 \%$ among treatment-naïve patients (CARE-MSI) and by $23 \%$, among patients with an inadequate response to prior DMT (CARE-MS II). ${ }^{20}$

During the 5-year extension phase of the CARE-MS I study, among 349 enrolled patients ( $95 \%$ of the original cohort) the low ARR was maintained and in $69 \%$ the EDSS remained stable or improved. ${ }^{21}$ The extension study of the CARE-MS II, which enrolled 393 patients (93\% of the original cohort) showed similar results. Over 5 years, the ARR remained stable and $65 \%$ had improved or stable EDSS. ${ }^{22}$ In addition, in both CARE MS-I and II extension studies, the positive effect on brain volume loss was sustained for 5 years. ${ }^{23}$

Several observational cohort studies confirmed the long-term efficacy of alemtuzumab. For example, among 87 patients followed in the UK for a mean 7 years, the mean ARR decreased from 1.78 (during the 2 years before starting treatment) to $0.16 .{ }^{24} \mathrm{In}$ addition, a larger proportion of patients $(43.5 \%)$ had a reduction in disability (defined as a 6-month sustained reduction in EDSS score of either $\geq 1.0$ or 0.5 for baseline EDSS scores below and above 5.5, respectively) than an accumulation of disability (32.2\%) (defined as 6 months sustained increase of $\geq 1.5$ EDSS points, if the baseline EDSS was 0 , of $\geq 1.0$ point, if baseline EDSS was $\geq 1$, but $<5.5$, or of $>0.5$ point when baseline was $\geq 5.5$, Figure 2 ). ${ }^{24}$ 
Overall, the mean EDSS remained stable over the observation period (3.6 at last follow-up compared with 3.8 at baseline).

Of the 108 patients originally enrolled in the phase II CAMMS223 study, which assessed the safety of alemtuzumab compared with IFN $\beta-1$,, $52 \%$ $(n=57)$ were observed for 10 years and received either two, three, four or five courses of treatment $\left(33 \%, 43 \%, 12 \%\right.$ or $10 \%$ respectively). ${ }^{25}$ The ARR remained low (0.08) and the mean EDSS change from baseline to year 10 was +0.12 point. In addition, $78 \%$ had stable or improved $(\leq 1$ point improvement) EDSS score.

A large amount of data on the long-term safety of alemtuzumab have been collected during the 4-year extension of the CARE-MS I-II studies, the 7-year extension of the CAMMS223 study and the 12-year observation study of the Cambridge cohort. ${ }^{26}$ During the phase II and III trials, in the group receiving alemtuzumab $12 \mathrm{mg}$, the rate of AEs was 7.2 to 8.7 per patient per year, and serious AEs were observed in 18-22\% of patients. A total of five deaths were reported: two in CAMMS223 (cardiovascular disease, immune thrombocytopenias [ITP]) one in CARE-MS I (automobile accident) and II in CARE-MS II (automobile accident and aspirational pneumonia following brainstem relapse). Infusion-associated reactions were the most common side effect $(\geq 90 \%)$, while infections (mostly mild or moderate) occurred in $66-77 \%$ of patients (45-66\% with subcutaneous IFN3-1a). Other reported AEs include malignancies, nephropathy, thyroid disease and ITP. Thyroid authoimmune AEs occurred in 39\% and 29\% of those treated with alemtuzumab (12 mg and $24 \mathrm{mg}$ respectively). ${ }^{26}$ Autoimmune AEs (autoimmune thyroid disorders) have been observed in $34.2 \%$ of patients from CAMMS223, but were generally predictable and effectively managed by rigorous monitoring. ${ }^{20}$ Overall, its safety profile is well characterised and established programmes for safety monitoring and education allow to manage effectively its AEs. ${ }^{27}$ Recent reports of rare AEs remind us of the need for continuous pharmacovigilance..$^{28}$

\section{Daclizumab}

Daclizumab was approved by the US Food and Drug Administration (FDA) and the European Medicines Agency (EMA) in 2016. It became available in England and Wales in 2017 for treating patients with RRMS with high active disease despite a full adequate course of treatment with at least 2 DMTs or for treating rapidly evolving severe relapsing MS, who are unsuitable for treatment with other DMTs. ${ }^{29-32}$ On 2 March 2018, Biogen and AbbVie voluntarily withdrew daclizumab from the market due to seven cases of serious inflammatory brain disorders (encephalitis and meningoencephalitis).

\section{Ocrelizumab}

Ocrelizumab was approved by the FDA in March 2017 and by the EMA in January 2018 for treating relapsing forms of multiple sclerosis (RMS) with active disease defined by clinical or imaging features. Ocrelizumab is also indicated for the treatment of adult patients with early primary progressive multiple sclerosis (PPMS) in terms of disease duration and level of disability and with imaging features characteristic of inflammatory activity. It is a humanised MAb that selectively targets CD20+ $\beta$ cells. ${ }^{33}$ The efficacy and safety of ocrelizumab were compared to IFN $\beta$-1a in two identical multicentre, randomised, double-blind, paralleled group, phase III studies (OPERA I, OPERA II), with 821 and 835 patients with relapsing MS enrolled, respectively (Table 1). ${ }^{34}$ In OPERA I, after 96 weeks, the ARR was significantly lower in the ocrelizumab group, compared with IFN $\beta$-1a (In OPERA II the ARR was also significantly lower). Furthermore, in a prespecified pooled analyses from both OPERA I and II, 9.1\% patients in the ocrelizumab treated group were found to have experienced sustained disability progression, compared with $13.6 \%$ in the
IFN $\beta$-1a treated group $(p<0.001)$. Ocrelizumab was also associated with a significantly larger reduction of new gadolinium-enhancing lesions (94\% lower with ocrelizumab than IFN $\beta-1 a ; p<0.001$ ) and improved MS Functional Composite score ( 0.28 versus. $0.17 ; p=0.004$ in OPERA I), although this was not significantly different among the two groups in OPERA II (0.21 versus. $0.17 ; p=0.33)$.

The ORATORIO, a multicentre, randomised, double-blind, placebo-controlled phase III trial, enrolled 732 patients with PPMS who received $600 \mathrm{mg}$ ocrelizumab or placebo and were followed up for almost 3 years. ${ }^{33}$ In comparison to the placebo-treated patients, a significantly smaller proportion of ocrelizumab-treated patients had 12-week confirmed disability progression (32.9\% versus $39.3 \% ; p=0.03$ ), or confirmed disability progression at 24 weeks (29.6\% versus $35.7 \%$; $\mathrm{p}=0.04$ ). In addition, the total brain T2 lesions volume decreased in patients treated with ocrelizumab, but increased in the placebo group $(p<0.001)$. In the timed 25 -foot walk test, ocrelizumab-treated patients worsened by $38.9 \%$ compared with placebo-treated patients, who worsened by $55.1 \%(p=0.04)$. No significant difference was observed in the change in the Physical Component Summary Score of the 36-Item Short-Form Health Survey.

In ORATORIO, the percentage of patients with at least one AE was $95.1 \%$ and $90.0 \%$ in the ocrelizumab and placebo groups, respectively. Serious AEs occurred in $20.4 \%$ of ocrelizumab-treated patients and $22.2 \%$ in the placebo group. Overall, Infusion-related reactions were the most frequent AEs (39.9\% versus $25.5 \%$ for ocrelizumab and placebo, respectively). ${ }^{33}$

AES associated with ocrelizumab in OPERA | and || included infusion-related reactions (34.3\% of patients), serious infections (1.3\% of patients versus $2.9 \%$ with IFN $\beta-1 a$ ) and neoplasms (0.5\% with ocrelizumab versus $0.2 \%$ with IFN $\beta-12) .{ }^{34}$ Neoplasms were reported in $0.5 \%$ and $0.2 \%$ of patients treated with ocrelizumab and IFN $\beta-1$, respectively. The death of a patient in the high-dose $(2,000 \mathrm{mg})$ group during a phase II trial raised concerns about the ocrelizumab safety profile, but an independent pathological review concluded that the patient showed no signs of viral infection and the systemic acute inflammatory reaction observed has not been proven to be the result of ocrelizumab treatment. ${ }^{35}$

There are several caveats associated with long-term outcomes. These include limited information regarding the outcomes (efficacy and safety) of patients that drop out, there is a natural regression to the mean in efficacy outcomes in long-term trials, efficacy is offset by any safety issues and real-world studies have inherent biases.

\section{Optimising outcomes in multiple sclerosis - treatment strategies}

Should monoclonal antibody therapy be used as first-line therapy or reserved for second-line use?

Early treatment initiation was shown to reduce the probability of experiencing a second attack and of preventing disability accumulation. ${ }^{36-41}$ However, the question whether an effective therapeutic suppression of the early inflammatory disease activity can prevent the onset of progression remains unresolved and the use of aggressive therapeutic strategies is still based on empirical evidence. ${ }^{6,42}$ The majority of patients with mildly to moderately active MS are initially managed with first-line treatments, which are advantaged by a good safety profile and availability of long-term safety data, and, if disease breakthrough occurs, are escalated to a stronger compound (Figure 3)..$^{43}$ Data on the direct comparison of efficacy, among 
Figure 3: Optimisation of the therapeutic approach

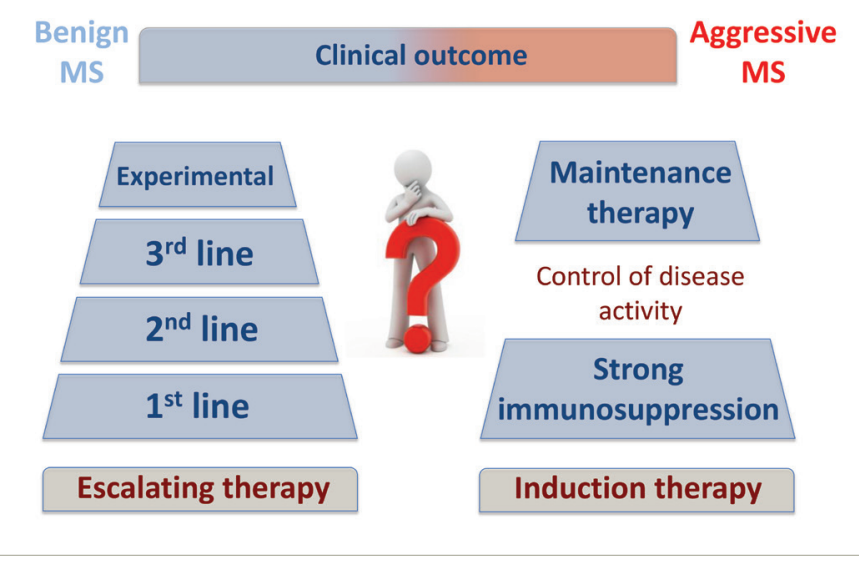

MS = multiple sclerosis. Reproduced with permission from Antonio Scalfari.

second-line drugs, are not available. Therefore, the decision on switching treatment should be primarily based on the patients' clinical situation and risk profile.

By adopting an escalating therapeutic approach, we might miss the opportunity of treating effectively in time those destined to have a severe disease course. However, identifying patients early in the disease course who might potentially benefit from an induction versus an escalating therapeutic strategy, remains challenging. ${ }^{42}$ Lessons from alemtuzumab observational studies suggest there might be an early window of therapeutic opportunity for MAbs to exert most of their efficacy. Successful suppression of the inflammatory activity achieved full stabilisation of the disease progression only when applied during the early stage. ${ }^{44}$ In line with these observations, MRI and natural history ${ }^{45-50}$ studies demonstrated that the early focal radiological and clinical inflammatory activity influence the long-term disease evolution. Patients with a high baseline T2 lesions load and a larger number of relapses during the first 2 and 5 years from onset are more likely to experience a faster disease progression. ${ }^{45-50}$ Overall evidence suggests that an early effective treatment might associate with a better control of the disease activity in the long-term, although a general consensus on how to optimise the therapeutic approach is still missing. ${ }^{51,52}$

\section{When to switch to monoclonal antibody therapy}

According to the 2015 Association of British Neurologists (ABN) guidelines, licensed DMTs can be divided into two categories based on their efficacy; one, moderate efficacy: IFN $\beta$ S, glatiramer acetate (GA), teriflunomide, dimethyl fumarate, fingolimod; two, high efficacy: alemtuzumab, natalizumab. ${ }^{53}$ Switching from moderate to high-efficacy category DMT may be justified when high-disease activity (one relapse in the previous year and either $\geq 1$ gadolinium-enhancing MRI lesion or at least 9 T2-hyperintense lesions on cranial MRI) occurs, or in some cases even if radiological disease breakthrough is not accompanied by any clinical relapse..$^{53}$

The 2018 European Committee for Treatment and Research in MS (ECTRIMS)/European Academy of Neurology (EAN) guidelines developed using the Grading of Recommendations Assessment, Development and Evaluation (GRADE) methodology produced clinical questions in the PICO format (patient, intervention, comparator, outcome). The guidelines provide recommendations based on available evidence and should provide homogeneity of treatment decisions throughout Europe. ${ }^{54}$ In total, 10 questions were formulated on treatment efficacy, response criteria, strategies to address suboptimal response and safety concerns and finally treatment strategies in MS and pregnancy. In particular, Question 6 involved discussion of switching between IFN and GA or changing to more efficacious DMTs (such as MAbs). Nine studies were considered for meta-analysis and as a result, recommendations 14 and 15 were proposed. Recommendation 14 had strong support to offer a more efficacious drug to patients on IFN or GA where there is evidence of disease activity. Recommendation 15 is a consensus statement recommending to consider patient characteristics and comorbidities; drug safety profile and disease severity/activity in the decision about therapy switching.

Giovannoni et al. have questioned whether no evidence of disease activity (NEDA) should be the treatment target among patients with MS. ${ }^{55}$ The new treat-to-target NEDA algorithm individualises the treatment by choosing between two interchangeable strategies of maintenance-escalation or induction therapy (Figure 4). ${ }^{55}$ The algorithm requires MRI assessment at re-baselining, after the specific DMT has had time to show efficacy, which normally is established within 6 months from therapy initiation. Disease activity while on the maintenance-escalation therapy implies a sub-optimal response, which requires consideration of switching or escalating therapy or moving to the induction option. Alternatively, switching to the maintenance-escalation therapy should be considered, when disease activity occurs despite the induction treatment.

Switching among treatments may require a wash-out period of generally 3 months before commencing the new drug. This might potentially expose patients to disease rebound. In addition, switching from natalizumab or fingolimod may require cerebrospinal fluid analysis prior to initiation of the new therapy in order to rule out PML infection, which could potentially and dangerously be carried over.

Evidence from observational studies indicated that, among patients experiencing clinical breakthrough while on first line treatments, switching to natalizumab is more effective than switching to another immunomodulator. The study compared patients who had relapsed on IFN $\beta$ or GA and were switched to natalizumab or IFN $\beta / G A \leq 6$ months after discontinuing prior therapy.56 During the first year of observation, switching to natalizumab, compared to switching between IFN $\beta$ and GA, resulted in a reduction of the ARR (by $65-75 \%$ ) and of the risk of having further relapses (by 53-82\%) - $p \leq 0.001$ for all comparisons. In addition, during the first 24 months after switching therapy, patients on natalizumab had a lower risk of confirmed disability progression (by $26 \% ; p=0.036$ ) and a reduction of the total disability burden (by 1.54 EDSS-years; $p<0.0001$ ).

Data from the MSBase registry showed that, among patients experiencing relapses or disability progression while on injectable DMTs, switching to natalizumab can achieve a better disease control, compared with switching to fingolimod. ${ }^{57}$ Propensity score-based matching was used to select 578 patients with similar baseline characteristics. After a mean follow-up of 12 months, ARRs were 0.2 and 0.4 for natalizumab and fingolimod, respectively, with a $50 \%$ relative post-switch difference in relapse hazard $(p=0.002)$. The rate of sustained disability regression (regression of $\geq 1$ EDSS sustained for $\geq 6$ months) was 2.8 times higher with natalizumab than with fingolimod $(p<0.001)$ and the change in disability burden was 0.12 versus 0.04 with natalizumab and fingolimod, respectively $(p<0.001)$. 


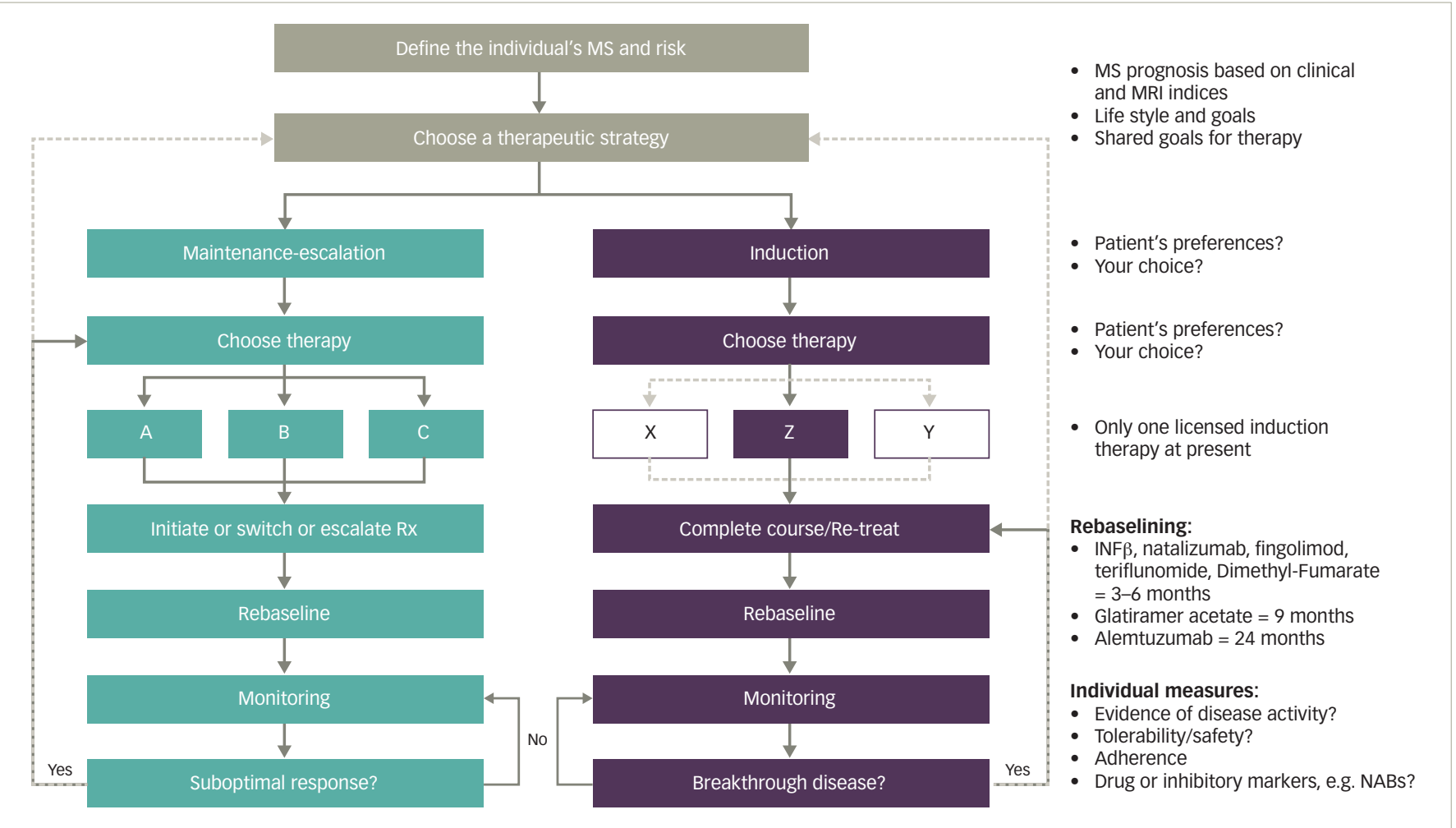

IFN $\beta=$ interferon beta; $M S=$ multiple sclerosis; $N A B S=$ neutralising antibodies; $N E D A=$ no evident disease activity. Reproduced with permission from Giovannoni et al., 2015.5.

\section{Choosing optimum treatment in multiple sclerosis - likely effect on prognosis}

choosing the optimum treatment for a particular patient is problematic as many factors must be carefully weighed and the views of the individual patient should be considered. It is important that this decision is made jointly between the doctor and patient. Treatment algorithms are available to the neurologist and provide guidance for these decisions, but the experience and skill of the neurologist will always remain crucial to arrive at the optimum treatment for each patient.

Using data from RRMS propensity-matched patients, followed for 5 years at 71 MSBase centres in 21 countries and at non-MSBase centres in the UK and Germany, the efficacy of alemtuzumab, natalizumab, fingolimod and IFN $\beta$ was compared. ${ }^{58} A$ total of 189 , $2,155,828$ and 1,160 patients received alemtuzumab, IFN $\beta$, fingolimod or natalizumab respectively. The use of alemtuzumab was associated with a lower ARR, compared with IFN $\beta(0.19$ versus $0.53, p<0.0001)$ and with fingolimod $(0.15$ versus $0.34, p<0.0001)$, although it was similar to natalizumab $(0.20$ versus $0.19, p=0.78)$. The probability of experiencing disability accumulation was not significantly different among groups. However, disability improvement was more likely to occur in the natalizumab group, compared with the alemtuzumab group (EDSS improvement 0.59 versus $0.35 ; p=0.0006$ ).

An independent, multicentre, post-marketing study evaluated the effectiveness of natalizumab, fingolimod and injectable DMTs among patients with inadequate response to the first immunomodulating therapy ( $n=567$ ) and among treatment-naïve patients with highly active disease $(n=216) .{ }^{59}$ The primary outcome measure was NEDA-3 (absence of relapses, disability worsening and radiological activity), assessed 24 months after switching DMT in non-responders or after starting high-dose IFN $\beta$. In the non-responder cohort, the proportion of patients with NEDA-3 was $67 \%, 42 \%$ and $35 \%(p=0.034)$, for the natalizumab, fingolimod and injection DMT groups, respectively. In patients with highly active disease, NEDA-3 was observed in $75 \%, 67 \%$ and $40 \%$ for the natalizumab, fingolimod and injection DMT groups respectively, but the difference was not statistically significant (probably due to small group sizes)

\section{Conclusions}

Each MAb treatment for MS has a unique biological structure and target, and accordingly a variety of mechanisms of action (MOA). The decision for the optimum therapy for a patient should be considered on an individual basis. ${ }^{60,61}$ Efficacy has to be carefully balanced with safety and other factors that influence the likely success of a treatment, such as adherence. Although earlier, more effective treatment is commonly used in patients who are likely to have a worse outlook or more rapid progression, there is no direct evidence of the long-term benefits. There is thus a need to collect long-term data in order to inform physicians and patients when choosing the optimal treatment.

The decision to treat MS with a MAb is multifaceted. Their superior efficacy compared with injectable treatments must be balanced against more serious side effects, which can be monitored. MAbs have the advantage of convenience and potentially better patient adherence, as they are administered by less frequent infusion, rather than injection daily or every few days, or daily oral dosing. It is also pertinent to consider the cost of these treatments compared with other therapies, which is a potential issue in many countries where healthcare budgets are under pressure. It should be noted, however, that for a more effective therapy the higher cost of treatment may be offset by reduction of costs related to disability progression and health care resource utilisation. 
Natalizumab, alemtuzumab and ocrelizumab are currently licensed for the treatment of MS, but in the next few years more MAb treatment options should be available. Ocrelizumab is the only licensed DMT for PPMS. Natalizumab and alemtuzumab are generally used as second-line treatments or in cases of aggressive disease. Their use as first-line treatments is open to debate, as the advantage of enhanced efficacy must be weighed against their risk. There is evidence that when disease breakthrough occurs with treatment using a first-line therapy, switching to a MAb rather than a different first-line therapy is probably the best option to control the disease activity.
1. Compston A, Coles A. Multiple sclerosis. Lancet. 2008;372;1502-17

2. Scalfari $A$, Neuhaus $N$, Daumer, $M$, at al. Onset of secondary progressive phase and long-term evolution of multiple sclerosis. J Neurol Neurosurg Psychiatry. 2014;85:67-75.

3. Trapp BD, Peterson J, Ransohoff RM, et al. Axonal transaction in the lesions of multiple sclerosis. N Eng/ J Med.1998;338:278-85 Lassmann $\mathrm{H}$, van Horssen J, Mahad D. Progressive multiple sclerosis: pathology and pathogenesis. Nature Reviews Neurol. 2012:8:647-56.

5. Wingerchuk DM, Weinshenker BG. Disease modifying therapies for multiple sclerosis. BMJ. 2016;354:i3518.

6. FoX EJ, Rhoades RW. New treatments and treatment goals for patients with relapsing-remitting multiple sclerosis. Curr Opin Neurol. 2012;25 Suppl.:S11-9.

7. Polman $\mathrm{C}, \mathrm{O}^{\prime} \mathrm{C}$ (nnnor PW, Havrdova E, et al. A randomized, placebo-controlled trial of natalizumab for relapsing multiple sclerosis. N Eng/ J Med. 2006;354:899-912.

8. Miller $\mathrm{DH}$, Soon $\mathrm{D}$, Fernando $\mathrm{KT}$, et al. MRI outcomes in a placebo-controlled trial of natalizumab in relapsing MS. Neurology 2007:68:1390-401.

9. Planas R, Martin R, Sospedra M. Long-term safety and efficacy of natalizumab in relapsing-remitting multiple sclerosis: impact on quality of life. Patient Relat Outcome Meas. 2014:5:25-33.

10. O'Connor P, Goodman A, Kappos L, et al. Long-term safety and effectiveness of natalizumab redosing and treatment in the STRATA MS study. Neurology. 2014:83:78-86.

11. Rudick R, Goodman A, Kappos $L$, et al. Six-year natalizumab safety and efficacy data from STRATA study. Presented at: 29th Congress of the European Commitee for Treatment and Research in Multiple Sclerosis, Copenhagen, Denmark, 2-5 October, 2013. Abstr \# 34073.

12. Butzkueven H, Kappos L, Pellegrini F, et al. Efficacy and safety of natalizumab in multiple sclerosis: interim observational programme results. I Neurol Neurosurg Psychiatry. 2014;85:1190-7.

13. Fernández O, Garcia-Merino JA, Arroyo R, et al. Spanish consensus on the use of natalizumab (Tysabri $)^{\text {) }}-2013$. Neurologicia. 2015;30:302-14

14. Havrdova $\mathrm{E}$, Galetta $\mathrm{S}$, Hutchinson $\mathrm{M}$, et al. Effect of natalizumab on clinical and radiological disease activity in multiple sclerosis: a retrospective analysis of the Natalizumab Safety and Efficacy in Relapsing-Remitting Multiple Sclerosis (AFFIRM) study. Lancet Neurol. 2009;8:254-60.

15. Prosperini L, Fanelli F, Pozzilli C. Long-term assessment of no evidence of disease activity with natalizumab in relapsing multiple sclerosis. J Neurol Sci. 2016;364:145-7.

16. Belachew S, Phan-Ba R, Bartholomé E, et al. Natalizumab induces a rapid improvement of disability status and ambulation after failure of previous therapy in relapsing-remitting multiple sclerosis. Eur 」 Neurol. 2011:18:240-5.

17. NYU Langone Health. Extending dosing intervals redues deadly side effect risk from popular multiple sclerosis drug. 2018. Available at: www.prnewswire.com/news-releases/extendingdosing-intervals-reduces-deadly-side-effect-risk-from-populardosing-intervals-reduces-deadly-side-effect-risk-from-popularmultip

8. Cohen JA, Coles AJ, Arnold DL, et a. Alemtuzumab versus interferon beta 1a as first-line treatment for patients with relapsing-remitting multiple sclerosis: a randomised controlled phase 3 trial. Lancet. 2012;380:1819-28.

19. Coles AJ, Twyman CL, Arnold DL, et al. Alemtuzumab for patients with relapsing-remitting multiple sclerosis after disease-modifying therapy: a randomised controlled phase 3 trial. Lancet. 2012;380:1828-39.

20. Hartung H-P, Aktas O, Boyko N. Alemtuzumab: A new therapy for active relapsing-remitting multiple sclerosis. Mult Scler. 2015;21:22-34

21. Havrdova E, Arnold DL, Cohen JA, et al. Durable efficacy of alemtuzumab on clinical outcomes over 5 years in treatment-naive patients with active relapsing-remitting multiple sclerosis with most patients not receiving treatment for 4 years: CARE-MS I extension study. Presented at: 31st Congress of the European Committee for Treatment and Research in Multiple Sclerosis, Barcelona, Spain, 2015. 7-10 October 2015. Abstr 152.

22. Fox EJ, Arnold DL, Cohen JA, et al. Durable efficacy of alemtuzumab on clinical outcomes over 5 years in CARE-MS II with most patients free from treatment for 4 years Presented at: 31st Congress of the European Committee for Presented at: 31 st Congress of the European Committee for
Treatment and Research in Multiple Sclerosis, Barcelona, Spain Treatment and Research in Multip

23. Barkhof F, Cohen JA, Coles A, et al. Alemtuzumab slows brain volume loss over 5 years in patients with active relapsing-remitting multiple sclerosis with most patients not receiving treatment for 4 years: CARE-MS I and II extension study. Presented at: 31st Congress of the European Committee for Treatment and Research in Multiple Sclerosis, Barcelona, Spain, 7-10 October 2015. Abstr 151

24. Tuohy O, Costelloe L, Hill-Cawthorne G, et al. Alemtuzumab treatment for multiple sclerosis: long-term safety and efficacy. J Neurol Neurosurg PSychiatry. 2015;86:208-15.

25. Selmaj KW Habek M Bass AD et al. Efficacy and safety of alemtuzumab in patients with RRMS is durable over 10 years: follow-up from the CAMMS223 study. Presented at: 32 nd Congress of the European Committee for Treatment and Research in Multiple Sclerosis, London, UK, 14-17 September 2016. Abstr P679

26. Havrdova E, Horakova D, Kovarova I. Alemtuzumab in the treatment of multiple sclerosis: key clinical trial results and considerations for use. Ther Adv Neurol Disord. 2015;8:31-45.

27. Van Wijmeersch B, Oreja-Guevara C, Milo R. Can we offer more to patients with multiple sclerosis? EU Neurol Rev. 2015;10:139-47.

28. Muraro PA, Scolding NJ, Fox RJ. Rare side effects of alemtuzumab reming us of the need for postmarketing surveillance. Neurology 2018:90:819-820.

29. Milo R. The efficacy and safety of daclizumab and its potentia role in the treatment of multiple sclerosis. Ther Adv Neurol Disord. 2014:7:7-21.

30. Gold R, Giovannoni G, Selmaj K, et al. Daclizumab high-yield process in relapsing-remitting multiple sclerosis (SELECT): a randomised, double-blind, placebo-controlled trial. Lancet. 2013;381:2167-75

31. Phillips $\mathrm{G}$, Guo $\mathrm{S}$, Bender R, et al. Assessing the impact of multiple sclerosis disease activity and daclizumab HYP treatment on patient-reported outcomes: Results from the SELECT trial. Mult Scler Relat Disord. 2016;6:66-72.

32. Kappos L, Weindl H, Selmaj K, et al. Daclizumab HYP versus interferon beta-1a in relapsing multiple sclerosis. N Eng/ J Med. 2015;373:1418-28

33. Montalban $\mathrm{X}$, Hauser $\mathrm{SL}$, Kappos $\mathrm{L}$, et al. Ocrelizumab versus placebo in primary progressive multiple sclerosis. N Eng/ J Med. 2017;376:209-20.

34. Hauser SL, Bar-Or A, Comi G, et al. Ocrelizumab versus interferon beta-1a in relapsing multiple sclerosis. N Eng/ J Med. 2017;376:221-34

35. Chaudhuri A. Ocrelizumab in multiple sclerosis: risks and benefits. Lancet. 2012;379:1196-7.

36. Comi G, Filipi M, Barkof F, et al. Effect of early interferon treatment on conversion to definite multiple sclerosis: a randomised study. Lancet. 2001;357:1576-82.

37. Kappos L, Freedman MS, Polman CH, et al. Effect of early versus delayed interferon beta-1 $\mathrm{b}$ treatment on disability after a first clinical event suggestive of multiple sclerosis: a 3-year follow-up analysis of the BENEFIT study Lancet. 2007;370:898-97.

38. Comi G. Shifting the paradigm toward early treatment of multiple sclerosis with interferon beta. Clin Ther. 2009;31:1142-57.

39. Jacobs LD, Beck RW, Simon JH, et al. Intramuscular interferon beta-1a therapy initiated during the first demyelinating event in multiple sclerosis. CHAMPS Study Group. N Eng/ I Med. 2000;343:898-904.

40. Kappos L, Freedman MS, Polman CH, et al. Long-term effect of early treatment with interferon beta- $1 \mathrm{~b}$ after a first clinica event suggestive of multiple sclerosis: 5 -year active treatment extension of the phase 3 BENEFIT trial. Lancet Neurol. 2009:8:987-97.

41. Bermel RA, You X, Foulds $P$, et al. Predictors of long-term outcome in multiple sclerosis patients treated with interferon B. Ann Neurol. 2013;73:95-103.

42. Edan $\mathrm{G}$, Le Page $\mathrm{E}$. Induction therapy for patients with multiple sclerosis: Why? When? How? CNS Drugs. 2013;27:403-9.

43. Dörr J, Paul F. The transition from first-line to second-line therapy in multiple sclerosis. Curr Treat Options Neurol. 2015;17:354.

44. Coles AJ, Cox A, Le Page E, et al. The window of therapeutic opportunity in multiple sclerosis: evidence from monoclonal antibody therapy. J Neurol. 2006;235:98-108.

45. Fisniku LK, Brex PA, Altmann DR, et al. Disability and T2 MRI lesions: a 20-year follow-up of patients with relapse onset of multiple sclerosis. Brain. 2008;131:808-17.

46. Tintore M, Rovira A, Rio J, et al. Defining high, medium and low impact prognostic factors for developing multiple sclerosis. Brain. 2015:138:1863-74.

47. Confavreux $C$, Vukusic $S$, Adeleine P. Early clinical predictors and progression of irreversible disability in multiple sclerosis: an amnesic process. Brain. 2003;126:770-82.

48. Tremlett $\mathrm{H}$, Yousefi M, Devonshire V, et al. Impact of multiple sclerosis relapses on progression diminishes with time. Neurology. 2009;73:1616-23.

49. Scalfari A, Neuhaus A, Degenhardt A, et al. The natural history of multiple sclerosis: a geographically based study 10: relapses and long-term disability. Brain. 2010;133:1914-29.

50. Leray E, Yaouanq J, Le Page E, et al. Evidence for a two-stage disability progression in multiple sclerosis. Brain. 2010;133:1900-13.

51. Freedman M. Long-term follow-up of clinical trials of multiple sclerosis therapies. Neurology. 2011;76(Suppl. 1):S26-34.

52. Comi G. Clinically isolated syndrome: the rationale for early treatment. Nat Clin Pract Neurol. 2008;4:234-5.

53. Scolding N, Barnes D, Cader S, et al. Association of British Neurologists: revised (2015) guidelines for prescribing disease-modifying treatments in multiple sclerosis. Pract Neurol. 2015;0:1-7.

54. Montalban X, Gold R, Thompson A, et al. ECTRIMS/EAN guideline on the pharmacological treatment of people with multiple sclerosis. Eur J Neurol. 2018;25:215-37

55. Giovannoni G, Turner B, Gnanapavan S, et al. Is it time to target no evident disease activity (NEDA) in multiple sclerosis? Mult Scler Related Disord. 2015;4:329-33.

56. Spelman T, Kalincik T, Zhang A, et al. Comparative efficacy of switching to natalizumab in active multiple sclerosis. Ann Clin Trans/ Neurol 2015:2.373-87.

57. Kalincik T, Horakova D, Spelman T, et al. Switch to natalizuma versus fingolomod in active relapsing-remitting multiple sclerosis. Ann Neurol. 2015:77:425-35.

58. Kalincik T Brown JWL Robertson N et al Treatment effectiveness of alemtuzumab compared with natalizumab, fingolimod and interferon beta in relapsing-remitting multiple sclerosis: a cohort study. Lancet Neurol. 2017;16:271-81.

59. Prosperini L, Saccà F, Cordioli C, et al. Real-world effectiveness of natalizumab and fingolimod compared with self-injectable drugs in non-responders and in treatment-nailve patients with multiple sclerosis. J Neurol. 2017;264:284-94.

60. Lycke J. Monoclonal antibody therapies for the treatment of relapsing-remitting multiple sclerosis: differentiating mechanisms and clinical outcomes. Ther Adv Neurol Disord. 2015:8:274-93.

61. D'Amico E, Caserta C, Patti F. Monoclonal antibody therapy in multiple sclerosis: critical appraisal and new perspectives Expert Rev Neurother. 2015:15:251-68. 